\title{
Significados Construídos acerca das Instituições Socioeducativas: Entre o Imaginado e o Vivido
}

\author{
Andréa Sandoval Padovani - Universidade Federal da Babia e Faculdade Maurício de Nassau, Salvador, Brasil \\ Marilena Ristum - Universidade Federal da Babia, Salvador, Brasil
}

\begin{abstract}
Resumo
Este trabalho teve por objetivo compreender como adolescentes autores de ato infracional, cumprindo medida socioeducativa de internação, significam a internação. Utilizou-se, como aporte teórico, a Psicologia Histórico-Cultural, que concebe a construção social da pessoa em uma relação dialética. A fotovoz foi o instrumento utilizado para a coleta de dados, tendo sido solicitado que fotografassem o que percebiam como significativo. Após a revelação das fotos, foram realizados encontros nos quais os adolescentes puderam falar sobre as imagens. Os resultados destacam a visão dos adolescentes sobre o julgamento social a respeito das unidades de internação e dos adolescentes que dela fazem parte. A análise permitiu perceber que existe uma tentativa, por parte desses sujeitos, de modificar os significados construídos acerca dessas instituições e, consequentemente, minimizar o preconceito imposto pela sociedade. Essa mudança pode ser um dos caminhos possíveis para que o adolescente venha a estabelecer um convívio social distanciado da vivência infracional.

Palavras-chave: adolescência, medidas socioeducativas, privação de liberdade, significados-sentidos, fotovoz.
\end{abstract}

Constructed Meanings about Socio-Educational Institutions: Between what is Imagined and what is Lived

\begin{abstract}
This study had the purpose to understand how felon adolescents serving some socio-educational measure, understand the internment and the deprivation of freedom. The theoretical approach of Cultural-Historical Psychology was used, which conceives the person's social construction in a dialectical relationship. The photo-voice technique was the instrument used for data collection, in which they were requested to photograph what they perceive as significant. After developing those photos, there were some meetings where the adolescents could talk about the photos. The results highlight the adolescents' perception of the social judgment of the internment units and the adolescents who are part of those units. The analysis allowed us to realize that there is an attempt by these adolescents to modify the constructed meanings about these institutions and, therefore, minimize the prejudice imposed by society. This change can be one of the possible ways for the adolescent to establish a social life distant from the infraction experience.

Keywords: adolescence, socio-educational measures, deprivation of freedom, meanings-senses, photo-voice
\end{abstract}

Significados de las Instituciones Socioeducativas construídas sobre: entre el Imaginario y la Duración

\begin{abstract}
Resumen
Este estudio tuvo como objetivo entender cómo los adolescentes delincuentes cumpliendo medidas socioeducativas de internación, viven y sienten la internación. Se utilizó como aporte teórico la Psicología Histórico-Cultural, que concibe la construcción social de la persona en una relación dialéctica. Fotovoz fue el instrumento utilizado para la recolección de datos y se les pidió que fotografiasen lo que percibían significativo. Después de la revelación de las fotos fueron realizados encuentros en los cuales los adolescentes pudieron hablar sobre las imágenes. Los resultados destacan la visión de los adolescentes de cómo las personas juzgan las unidades de internación y a los adolescentes que forman parte de ellas. El análisis permitió percibir que existe un intento por parte de estos adolescentes, de modificar los significados construídos sobre esas instituciones y minimizar el prejuicio impuesto por la sociedade. Este cambio puede ser uno de los caminos posibles para que el adolescente establezca una vida social distanciada de la experiencia delictiva.

Palabras-clave: adolescencia, medidas socioeducativas, privación de libertad, significados-sentidos, fotovoz
\end{abstract}

\section{Adolescer}

A adolescência é considerada, por muitos estudiosos do tema, como um momento importante na construção da identidade. Essa construção, para o adolescente privado de liberdade, relaciona-se não somente ao fato de estar cumprindo uma medida de internação e, portanto, distante do convívio social extenso, mas está envolvida pelo (pré)conceito existente sobre as instituições prisionais e que abarca a figura do adolescente autor de ato infracional. Pautado nessas relações, o adolescente em privação de liberdade, ao tentar modificar os significados construídos acerca das instituições e dos adolescentes que as vivenciam, busca ressignificar sua própria identidade. $\mathrm{O}$ homem, ao agir sobre sua realidade, procura, por meio dessa ação, criar novas condições para sua vivência, firmando a vinculação entre indivíduo e sociedade na construção de significados e sentidos (Ristum, 2001; Vigotski, 1978/2003).

A adolescência e os fenômenos que a envolvem apresentam-se com diferentes configurações ao longo da história. Os significados sociais acerca da adolescência são singulares e suas características são próprias, em 
face do período histórico, da sociedade e da cultura da qual fazem parte. Este trabalho, em contraposição a visões estereotipadas, naturalizantes e universalizantes da adolescência, adotou a perspectiva de que a adolescência é construída social e historicamente e, assim sendo, tem seu significado determinado pela cultura e pela linguagem, que são mediadoras das relações sociais. É também, nessa perspectiva, que foi assumida a construção histórica dos significados acerca das instituições responsáveis por acolher os adolescentes autores de ato infracional e do próprio adolescente que vivencia essas instituições ao cumprir medidas que envolvem a privação de liberdade.

As ações do adolescente, segundo Vigotski (1931/2006), estão pautadas na relação com a realidade que o cerca e esta irá moldar sua forma de ver e agir no mundo. Essa relação amplia os significados que tem sobre a realidade, além de expandir a possibilidade de criar e/ou modificar uma situação. Essas mudanças se pautam em eventos experenciados pelos indivíduos durante o processo de desenvolvimento, processo que se refere à apropriação da cultura, dos modos de agir, de pensar e de se relacionar consigo e com os outros, e se coloca em oposição a um ponto de vista naturalista (Santos, 2010).

Vigotski (1931/2006) afirma que é na adolescência que o indivíduo toma consciência de si e essa autoconsciência é base para o autodomínio do comportamento, representando o desenvolvimento cultural deste. A teoria vigotskiana defende, portanto, que o ser humano se desenvolve e se atualiza, constituindo-se ao longo de sua história de vida, a partir de suas relações, por meio da significação dada ao que é vivenciado e que, dialeticamente, transforma a realidade (Bock, Gonçalves, \& Furtado, 2011; Vigotski, 1978/2003, 1986/1995).

\section{O Adolescente e o Ato Infracional}

$\mathrm{O}$ adolescente autor de ato infracional, ao vivenciar o julgamento social, poderá internalizar os (pré) conceitos acerca de si, podendo cristalizá-los em sua identidade e concretizá-los por meio da manutenção do comportamento "infrator". Nesse sentido, a medida socioeducativa, e as atividades por ela impostas, pode tornar-se mediadora na construção de uma nova identidade, possibilitando comportamentos que o distancie da vivência infracional.

Ao longo da história, os modelos jurídicos para lidar com adolescentes no Brasil sofreram transformações e, atualmente, ao infringir a lei, os adolescentes estão sujeitos ao cumprimento de medidas socioeducativas
(MSE). O Estatuto da Criança e do Adolescente - ECA (Brasil, 1990/2000), em sua segunda parte, e o Sistema Nacional Socioeducativo - SINASE (2012), dispõem sobre as diretrizes da política de atendimento aos adolescentes que cometeram ato infracional. Atendimento que deve ser dado por meio de medidas definidas pelo Juiz da Infância e da Juventude, cuja decisão deve ser livre do enfoque penalista e deve considerar as circunstâncias e a gravidade do ato, bem como as condições pessoais do adolescente, privilegiando um caráter social e educativo.

As medidas socioeducativas visam, portanto, a educação, a socialização e a integração do adolescente no convívio com o mundo que o cerca. Escolheu-se tratar, nesta pesquisa, da medida privativa de liberdade por esta ser a de maior impacto na vida dos sujeitos que a vivenciam, conforme indicam nossos estudos anteriores e a literatura sobre o tema (Goffman, 1961/2001; Silva, 2009; Padovani, 2013; Silva, Ruzzi-Pereira \& Pereira, 2013), além da experiência profissional junto a esse modelo de atendimento.

No Brasil, segundo o Levantamento Nacional do Atendimento Socioeducativo ao Adolescente em Conflito com a Lei ${ }^{1}$, realizado em Dezembro de 2010 (último ano em que foi realizado levantamento sobre o tema), existiam 17.703 adolescentes cumprindo medidas socioeducativas com restrição de liberdade. Esse levantamento demonstrou um crescimento de 1,18\% desses adolescentes, em relação ao ano anterior.

Fatores como o aumento do consumo e, portanto, do tráfico de drogas, além do crescimento financeiro e populacional dos grandes centros urbanos, aumentando as desigualdades socioeconômicas já existentes, podem ter contribuído para o maior envolvimento em atos infracionais. Porém, não se pode deixar de levantar a hipótese da crescente "cultura prisional" que abarca cidades do interior as quais, a cada dia, encaminham mais adolescentes para cumprir medida de internação em detrimento de medidas em meio aberto. No entanto, faz-se necessária uma análise mais profunda para que essas suposições possam ser confirmadas.

Mas vale ressaltar que a proporção de adolescentes em privação de liberdade (12.041), em relação ao número total de adolescentes na população brasileira (21 milhões), não ultrapassa 0,6\%. No Brasil, dados

\footnotetext{
${ }^{1}$ Secretaria Especial dos Direitos Humanos (2011). Levantamento Nacional do Atendimento Socioeducativo ao Adolescente em Conflito com a Lei. Brasília. Esse documento apresenta um conjunto de dados fornecidos pelos gestores estaduais do sistema socioeducativo em relação à aplicação das medidas socioeducativas.
} 
relativos aos adolescentes autores de ato infracional ainda são muito incipientes, dificultando conclusões acerca do tema. Um dado praticamente inexistente, por exemplo, refere-se ao índice de reincidência, que demonstra o número de adolescentes que, após cumprir medidas socioeducativas, voltam a cometer atos infracionais, fato que dificulta, ainda mais, analisar a eficácia das medidas na vida dos adolescentes que as cumprem.

\section{Unidades de Internação: Socioeducação $\times$ Punição}

As unidades responsáveis por atender adolescentes que cometeram ato infracional, em regime de internação, podem ser comparadas às chamadas, por Goffman (1961/2001), de "instituições totais". Conforme o autor, essas são instituições organizadas para proteger a sociedade contra perigos intencionais, sendo que o bem-estar das pessoas, nelas isoladas, não constitui um problema imediato. Ainda, conforme o autor, nas instituições totais existe uma divisão básica: o "grupo controlado, que podemos denominar de internados, e uma pequena equipe de supervisão" (p.18), sendo que ambos tendem a reconhecer o outro por meio de estereótipos impostos tanto pela sociedade como pela própria dinâmica institucional.

No caso da unidade de internação pesquisada, os adolescentes vivenciam essa divisão, bem como o sentimento de isolamento social, já que têm contato controlado com o mundo externo. Para o autor, "em nossa sociedade, [as instituições totais] são as estufas para mudar pessoas" (Goffman, 1961/2001, p. 22). Ao chegar a uma instituição, o indivíduo tem uma concepção de si, contudo, ao passar por mudanças nas crenças sobre si mesmo e sobre os outros que lhes são significativos, sofre o que o autor chama de "mortificação do eu".

Durante toda a humanidade, diversas foram as maneiras de "tratar" os indivíduos que infringiam a lei. Foucault (1975/1987) aponta que a definição das infrações, seu grau de gravidade, o tolerado e o permitido, tudo isso se modificou amplamente ao longo da história. Refere que o enfoque da lei e, portanto, das penas, até o século XIX se voltava para o crime, e o julgamento se dava de acordo com a gravidade do ato cometido, o que direcionava a pena a ser imposta. Contudo, a partir desse período, o júri passa a se voltar para o sujeito da pena, que é punido, a partir de então, não mais pelo ato, mas conforme suas características.

A própria penalidade, desenvolvida no século XIX, visava apenas afastar certos indivíduos nocivos à sociedade, objetivando o "controle e a reforma psicológica e moral das atitudes e do comportamento dos indivíduos" (Foucault, 1996/2002, p. 85) que não se enquadravam nas normas estabelecidas e, portanto, constituíam um risco ao convívio social. Em meados do século XIX, debates acerca das penalidades impostas aos criminosos, incluindo-se os adolescentes, foram travados no mundo todo e, com o objetivo de se repensar os sistemas prisionais e sua finalidade social, inúmeros documentos foram assinados por países que se comprometeram a discutir o tema de forma ampla e com vistas a atender as exigências internacionais sobre Direitos Humanos.

Com a criação do ECA, o debate sobre o adolescente autor de ato infracional chegou ao ápice, trazendo consigo a preocupação sobre como as instituições atenderiam às reais necessidades desses adolescentes, de modo a criar um sistema diferente do até então existente. Com a mudança da legislação e com as mudanças que se fizeram necessárias após a promulgação do ECA (Brasil, 1990/2000), ocorreu uma transformação no modo de ver, pensar e agir em relação a esses adolescentes, trazendo, às instituições responsáveis por abrigá-los, o papel de acolher e proteger, em oposição ao papel apenas punitivo e coercitivo. Uma das grandes mudanças propostas pelo Estatuto talvez tenha sido a ideia de que sem uma rede articulada e solidária entre todos os envolvidos (judiciário, governos, conselhos de direito, família, sociedade, etc.) tornam-se improváveis intervenções bem-sucedidas. Essa transformação, porém, pautou-se mais no âmbito teórico que na prática real dentro das instituições. Foram mudanças radicais e pontuais na ideologia, entretanto, poucas mudanças concretas no cotidiano e nas políticas voltadas ao atendimento (Gonçalves, 2011).

Tratar os adolescentes autores de ato infracional como "bandidos" é uma prática que carrega em seu bojo uma longa história, desde a criação dos "reformatórios" até grande parte das atuais instituições voltadas ao cumprimento de medidas socioeducativas. No entanto, as mudanças na legislação trouxeram debates, avanços e mostraram sensíveis progressos na proposição e implantação de novos modelos de atendimento pautados na socioeducação e na garantia de direitos. Entretanto, em sua maioria, as instituições não têm conseguido tratar os adolescentes com dignidade, com responsabilidade, assumindo a tarefa não apenas de "tirá-los" da criminalidade ou do círculo violento no qual estão inseridos, mas de, principalmente, conhecer as motivações, a realidade que os levou até esse momento, a sua trajetória de envolvimento infracional 
(Nuñez \& Pernas, 2010). Essa tarefa, no entanto, requer que toda a sociedade se veja responsável pela realidade desses adolescentes e isso vai muito além de mudar apenas o discurso e o olhar sobre eles, requer novas práticas na forma de lidar com essa realidade.

No caso dos adolescentes autores de ato infracional, os significados construídos ao longo da história e de suas próprias histórias individuais, têm implicações diretas sobre como esses adolescentes significam sua realidade diante da privação de liberdade.

Assim, julga-se que conhecer como esses adolescentes vivenciam a internação, e o processo que a envolve, pode significar um avanço na construção de um novo olhar sobre eles e sobre as instituições que os acolhem, bem como sobre as políticas públicas voltadas a essa população. Esse conhecimento pode ser um passo para que esses sujeitos possam ser vistos além do ato infracional, como indivíduos e como sujeitos de direitos.

\section{Objetivos}

O objetivo geral deste trabalho foi compreender e analisar como adolescentes autores de ato infracional, cumprindo medida socioeducativa de internação, significam a internação. Como objetivos específicos, buscou-se delinear como esses adolescentes percebem a internação em suas trajetórias de vida e como percebem a instituição socioeducativa, além de verificar como esses internos buscam ressignificar esses espaços, a partir de sua vivência na instituição.

\section{Construção de Significados}

Os significados são socialmente construídos, a partir da interpretação dada pelo sujeito em seu contexto sócio-histórico. Por meio da teoria vigotskiana, é possível compreender os processos cognitivos e os afetivos, os sociais e os individuais, de forma dialética, na qual sujeito e ambiente não são mais dicotômicos, mas fazem parte de uma mesma construção (Bock, Gonçalves, \& Furtado, 2011; Mesquita, 2005; Santos, 2010).

A experiência emocional, para Vigotski (1978/2003), irá interferir em como os indivíduos vivenciam e interpretam as situações e em suas ações diante da realidade, isto é, em como os sentidos são constituídos a partir da experiência individual, portanto, subjetiva. Contudo, essa relação não se apresenta como causa e efeito, mas como simultânea entre a situação, a interpretação dada, com base nesse momento da trajetória de vida, e como essa interpretação modifica a situação, portanto, a maneira particular com que o indivíduo se apropria dos significados sociais e lhes confere sentidos. Assim, significados e sentidos são produzidos em um processo contínuo, dialético, e de acordo com o contexto histórico-cultural em que o sujeito está inserido (Vigotski, 1978/2003).

A privação de liberdade passa por esse processo e o sentido dado pelo adolescente que a vivencia será construído a partir da relação do adolescente com o ambiente que o cerca, que envolve o olhar do outro e, portanto, as significações sociais. Segundo Vigotski (1978/2003), “a característica básica do comportamento humano em geral é que os próprios homens influenciam sua relação com o ambiente e, através deste ambiente, pessoalmente modificam seu comportamento" (p.68).

Pensa-se que usar significados e sentidos, para tentar compreender como os adolescentes percebem a privação de liberdade em sua história de vida, é uma forma de tentar chegar o mais próximo possível do pensamento desse adolescente. $O$ significado constitui a subjetividade e pode, portanto, ser utilizado para se chegar a ela, já que "as concepções das pessoas a respeito de um tema poderiam ser alcançadas através do significado, no qual estariam contidos os elementos desta concepção" (Ristum, 2001, p.128).

\section{Método}

Coerentemente com os pressupostos teóricos utilizados, optou-se por uma abordagem qualitativa, na qual o conhecimento ocorre por meio de uma produção construtiva-interpretativa, a partir dos significados dados pelos sujeitos às suas experiências, e de uma participação do pesquisador (Creswell, 2014), em "um processo em que o pesquisador integra, reconstrói e apresenta em construções interpretativas diversos indicadores obtidos durante a pesquisa, os quais não teriam nenhum sentido se fossem tomados de forma isolada" (González-Rey, 2002, p.31).

\section{Instituição}

A instituição em que se encontravam internados os sujeitos pesquisados é uma das 309 unidades de atendimento socioeducativo de internação do país, uma das quatro unidades de internação de um estado do Nordeste e atende apenas adolescentes do sexo masculino, sentenciados pelo cometimento de atos infracionais, como furto, roubo, tráfico de drogas, homicídio e latrocínio. Essa unidade está localizada 
em uma grande capital do país e tem capacidade para abrigar 120 adolescentes do sexo masculino, com idade entre 12 e 21 anos, conforme o Art. $2^{\circ}$ do ECA (Brasil, 1990/2000). No momento da pesquisa, atendia cerca de 70 adolescentes, na faixa etária de 14 a 19 anos, com predominância das idades entre 15 e 17 anos, dado que concorda com a literatura que relata uma maior incidência da prática de delitos nessa faixa de idade (Padovani, 2013; Volpi, 2002).

A unidade foi construída após a promulgação do ECA (Brasil, 1990/2000), o que lhe confere uma estrutura física mais próxima das novas recomendações propostas pela legislação e facilita a implantação da proposta pedagógica, aqui pautada na Pedagogia da Presença (Costa, 1997). Segundo o autor, o trabalho dos profissionais que atuam na unidade, independente de sua função, é a presença socioeducativa, cabendo a eles se fazerem presentes na vida do educando, buscando uma relação que ofereça um espaço de desenvolvimento tanto pessoal quanto social. Conta, ainda, com a equipe mínima prevista no SINASE (2012), além de não apresentar, no momento da pesquisa, a superlotação característica de algumas instituições socioeducativas, sendo considerada, pelos organismos envolvidos na execução de medidas socioeducativas, como uma unidade modelo.

\section{Participantes}

Os participantes desta pesquisa foram seis adolescentes com idade entre 16 e 19 anos, que cumpriam medida socioeducativa de internação (MSEI), entre seis meses e dois anos, e que concordaram em participar da pesquisa. A vivência infracional e o ato cometido apresentavam diferença entre os adolescentes pesquisados; alguns relataram uma trajetória na vida infracional e outros revelaram responder pelo primeiro cometido. Os atos praticados foram roubos, tráfico de drogas e homicídio. A maioria advinha do interior do estado, sendo que, apenas um deles, residia na capital. Todos viviam com suas famílias, em sua maioria, monoparentais, de baixa renda, sem acesso aos direitos básicos, como saúde, educação e moradia de qualidade, e estavam fora da escola no momento do cometimento do ato.

Tratou-se, portanto, de uma seleção não probabilística e voluntária, por escolha racional, já que o local, a unidade de análise e os procedimentos foram escolhidos para atender ao objetivo da pesquisa; também se caracterizou por ser proposital, já que os participantes foram selecionados por já terem vivenciado o fenômeno central estudado na pesquisa (Creswell, 2014; Metring, 2011).

\section{Instrumentos e Procedimentos}

A técnica utilizada para a coleta de dados foi a fotovoz. A fotovoz é uma técnica de pesquisa participativa em que câmeras são entregues aos participantes e estes são convidados a fotografar a realidade que os cerca e, em seguida, falar sobre essas fotografias. O uso da fotografia pode facilitar a expressão, auxiliando na comunicação dos significados que esses sujeitos têm acerca de um fenômeno e permitindo maior compreensão por parte do pesquisador sobre esses significados (Neiva-Silva \& Koller, 2002). De acordo com Melleiro e Gualda (2005), "a proposta de interpretação de fotografias é um ato de descrever um olhar persuasivo" (p.192). Para as autoras, a utilização das técnicas da fotografia e da entrevista posterior, de forma complementar, pode contribuir para melhor interpretar as narrativas. Os adolescentes receberam uma máquina fotográfica descartável de 24 poses e foram instruídos a fotografar, no prazo máximo de 15 dias, o que consideravam significativo na internação. Após a revelação das fotos, estas foram apresentadas aos participantes, individualmente, sendo solicitado que o adolescente relatasse os significados dessas imagens e os sentimentos, as emoções e as percepções em relação a elas. Foram realizados, em média, dois encontros com cada adolescente para a etapa de falar sobre as imagens. As entrevistas transcritas passaram por leitura e posterior extração dos temas e das categorias, sempre em consonância com os objetivos do trabalho. Os nomes são fictícios e foram escolhidos pelos adolescentes.

Esta pesquisa teve a aprovação do Comitê de Ética em Pesquisa da Faculdade de Enfermagem, da Universidade Federal da Bahia, estando em acordo com as normas estabelecidas pela resolução que regula a pesquisa com seres humanos.

O processo de análise, utilizado neste trabalho, consistiu em extrair sentido dos dados, em detrimento de um modelo analítico pré-concebido (Creswell, 2014), enquanto opção para o estudo dos significados produzidos pelas relações dentro dos contextos de vida. O objetivo do pesquisador, portanto, foi dar sentido aos dados, mas reconhecendo que sua formação e sua própria experiência pessoal, cultural e histórica, estavam presentes em sua interpretação, o que tornou o pesquisador inseparável da pesquisa (Creswell, 2014). 


\section{Resultados e Discussão}

Os adolescentes, ao fotografarem os aspectos significativos da unidade de internação, revelaram a internação enquanto punição, sofrimento, isolamento social, distanciamento familiar, porém, também procuraram tornar visíveis seus aspectos positivos, como o cuidado, o respeito, a possibilidade de estudar e de se profissionalizar. Demonstraram, assim, preocupação em mostrar uma realidade diferente do que é imaginado e percebido pela sociedade sobre essas instituições, buscando, com isso, construir novos significados acerca desses contextos, conferindo-lhes significados próprios, compartilhados pelos adolescentes dessa unidade, pois estão pautados na vivência cotidiana da instituição. Esses novos significados, construídos pelos sujeitos pesquisados, podem contribuir para mudar o julgamento social em relação à própria instituição, mas, principalmente, em relação aos adolescentes que dela fazem parte.

Os significados atribuídos pela sociedade às instituições socioeducativas, e que ainda fazem parte da realidade de muitas unidades no Brasil, interferem na maneira como os operadores de direito, incluindo-se os policiais responsáveis pela condução dos adolescentes, interpretam a medida socioeducativa de internação e, também, em como algumas unidades são vivenciadas pelos próprios adolescentes, como é mostrado no relato a seguir:

\begin{abstract}
Muitos pensam que (...) é estar na cadeia (...) primeira vez. que eu vim pra cá, os policiais mesmo que me trouxe falou que aqui era a FEBEM, já ouvin falar? FEBEM de São Paulo, um lugar bem, sem ninguém. (...) eu vi que o negócio não era fácil, no CAM é mais atribulado (...) aqui é mais tranquilo, mais sossegado (Xande, 16 anos).
\end{abstract}

A antiga FEBEM, nome dado às unidades que acolhiam adolescentes "infratores", no período de implantação da Política Nacional de Bem Estar do Menor $^{2}$, em 1964, caracteriza-se como a imagem que melhor apresenta o que a população imagina sobre as unidades de internação do país. Vistas como "universidades do crime" ou como o "inferno na terra", produziram o modelo de instituição que não funciona. Superlotação, ociosidade, sujeira, falta de respeito, punições físicas severas, total abandono e sofrimento

\footnotetext{
${ }^{2}$ Lei n 4.513/64 (1964, 01 de dezembro). Institui a Política Nacional de Bem Estar do Menor-PNEBEM. Brasília, DF. Recuperado de http://www.planalto.gov.br/ccivil_03/leis/1950-1969/L4513.htm.
}

são alguns dos aspectos que permeavam a vida nessas instituições e que ainda fazem parte da forma como a sociedade percebe as unidades de internação. Conforme nos relata Dinho, 19 anos:

\section{Eu pensava que era o pior lugar do mundo (...) que era praticamente o inferno (...) Muita gente chegava pra mim e dizia: você precisa conbecer (...) lá dentro é o inferno (...) você não vai conseguir ficar nem um mês (...) vai querer se matar e tudo mais.}

Essas instituições são percebidas, por grande parte da sociedade, conforme é apontado no discurso midiático, nos debates e nas conversas informais sobre o tema, como uma "cadeia" ou um "presídio" em que os adolescentes são mantidos aglutinados em pequenos espaços, ociosos durante a maior parte do tempo, e em que só aprendem a se aperfeiçoar na criminalidade. Esses significados que constroem o imaginário social se devem à forma como essas unidades foram historicamente construídas, pautadas no modelo prisional, em que a punição e o "tratamento" eram seus maiores objetivos.

Um fator que também colabora para a manutenção dos significados negativos construídos acerca da MSEI, conforme nos referimos anteriormente, se deve à forma como os meios de comunicação ainda veiculam as informações sobre esses estabelecimentos, supervalorizando seus pontos negativos e seus insucessos, salientando fatos como a superlotação, maus-tratos, rebeliões, reincidências, demonstrando as mazelas que envolvem o atendimento ao adolescente autor de ato infracional. Os casos bem-sucedidos, que não são raros, são divulgados de forma breve e esporádica e ocupam pouco espaço na mídia.

A maioria dos adolescentes, diante disso, fotografou a praça central para mostrar que a internação significa mais do que cadeia e tem aspectos físicos que remetem à beleza, diferente do que se imagina fora de seus muros: (figura 1) "Não é que nem o povo pensa que é só cadeia (..) tem coisas boas também. A unidade é bonita, um lugar saudável, não é como as pessoas ficam dizendo, que é um lugar feio, é bonito, tem muitas árvores" (Xande, 16 anos).

A realidade de maus tratos, de tortura e crueldade e, principalmente, de transgressão da lei pelas instituições que atendem adolescentes autores de ato infracional ainda se faz presente em grande parte desses estabelecimentos pelo país, conforme é apontado em documentos, como a Inspeção Nacional às Unidades de Internação de Adolescentes em Conflito com a Lei (Comissão Nacional de Direitos Humanos do Conselho 


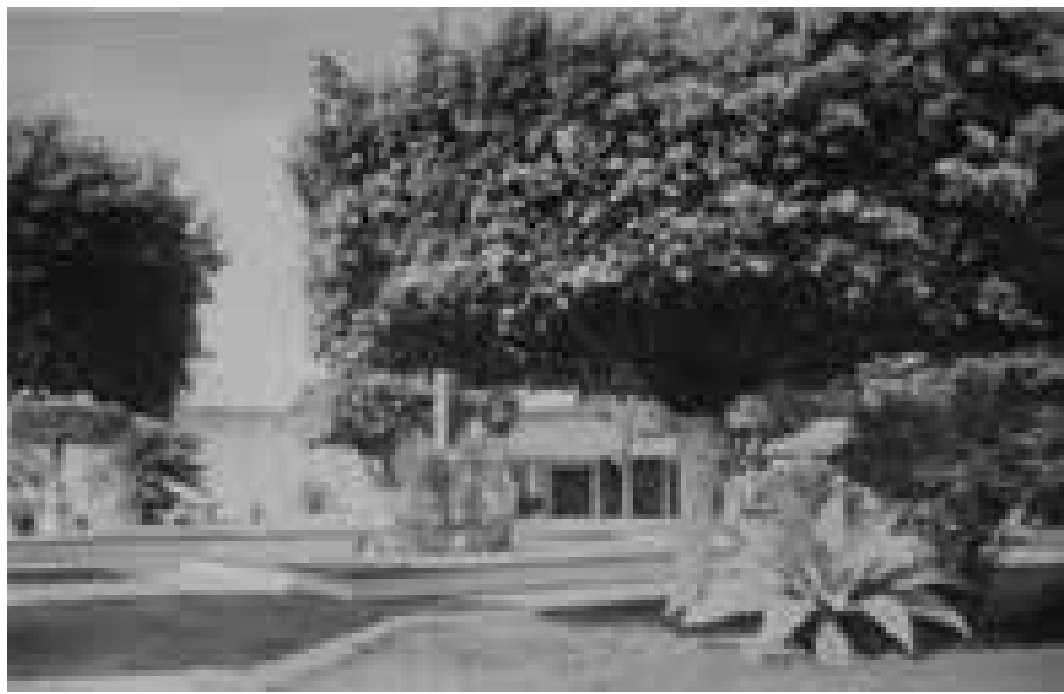

Figura 1. Praça central.

Federal de Psicologia (CNDH-CFP) \& Conselho Federal da Ordem dos Advogados do Brasil [CF-OAB], 2006) e o relatório Panorama Nacional: a execução das Medidas Socioeducativas de Internação ${ }^{3}$. Tanto na Inspeção Nacional quanto no relatório realizado pelo CNJ, o retrato que emerge é de "unidades superlotadas, projetos arquitetônicos semelhantes a presídios, presença de celas fortes e castigos corporais, ausência ou precariedade dos projetos sócio-educativos (...) dentre outros" (CNDH-CFP \& CF-OAB, 2006, p.14). Essa realidade, descrita em ambos os documentos, mesmo tendo entre eles um espaço de tempo de quase cinco anos, mostra que poucas mudanças concretas ocorreram.

A fala de Mário, 18 anos, ao comparar a unidade em que se encontrava no momento da pesquisa à outra unidade do sistema, na qual cumpriu oito meses da MSEI, demonstra que a tortura e a violência ainda fazem parte da realidade em algumas instituições: " $E$ ' diferente aqui, aqui as pessoas tratam com respeito. Orientador conversa e respeita. Lá (na outra) orientador espanca e agride, e os adolescentes agride orientador, é muita oprimissã $0^{4 ”}$.

\footnotetext{
${ }^{3}$ Estudo publicado e realizado pelo Departamento de Pesquisas Judiciárias do Conselho Nacional de Justiça [DPJ/CNJ]. (2012). Panorama Nacional. A execução das medidas socioeducativas de internação. Programa Justiça ao Jovem. Recuperado de http:// www.cnj.jus.br/images/pesquisas-judiciarias/Publicacoes/panorama_nacional_doj_web.pdf

4 “Oprimissão" é uma expressão usada pelos adolescentes para indicar um estado de opressão, em que adultos utilizam poder e força para oprimir os internos.
}

Muitos adolescentes, em suas falas, trouxeram a comparação da unidade com as delegacias e "cadeias" nas quais passaram algum tempo, mesmo esse procedimento contrariando a legislação, já que adolescentes só podem permanecer apreendidos em estabelecimentos apropriados para esse fim e nunca junto a adultos. A diferença mais apontada pelos sujeitos pesquisados se referiu às atividades desenvolvidas em oposição ao tempo ocioso das outras instituições, como demonstrado em outras pesquisas (Silva, 2009).

\section{Já tirei na delegacia (...) lá é veneno e aqui não é não. Porque lá tá dentro de uma cela (...) e o pátio é pequeno. Da cela pro pátio e do pátio pra cela (...) en fiquei lá sete meses (...) ai é veneno, é dificil, ele não pensa em mudar não, ele só fica pensando ali de fugir e de fazer outras coisas ruim. Aqui não, tem as coisas aqui, tem o lazer, ai o cara distrai a mente e não fica no veneno (...) ele fica pensando mais na vida, na maioria das vezes (...) agora em delegacia é dificil mudar, porque delegacia é veneno demais (Rafael, 17 anos).}

Além da ociosidade e da estrutura física inadequada, outro fator apontado pelos adolescentes se referiu ao tratamento violento prestado nas delegacias e cadeias públicas do interior do Estado e que ferem tanto os direitos do adolescente quanto os direitos humanos. Conforme relata Mário, 18 anos: "Porque as outras (delegacias) é diferente daqui, porque lá é uma cela, porque não tem atividade (...) é uma cadeia mesmo, a gente apanha muito".

Embora a unidade pesquisada também tivesse necessidades de ordem estrutural, conforme nos 


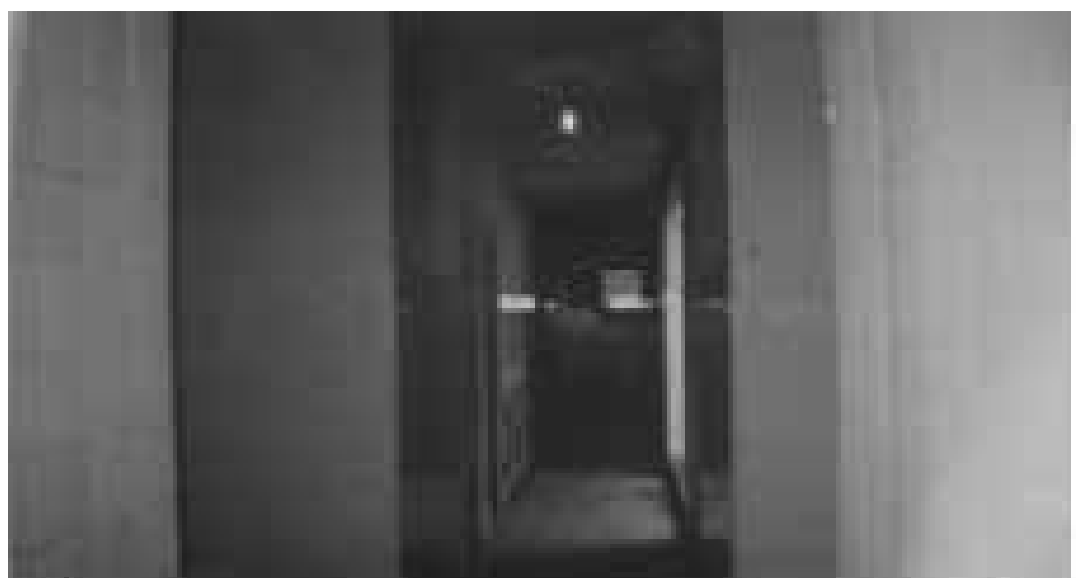

Figura 2. Corredor central do alojamento (casa).

colocou Mário, 18 anos, ao dizer que a "casa está precisando de uma reforma" e que os adolescentes "não consegue dormir direito por causa do calor e também os colchões, o armário tem que melhorar mais", a maioria dos adolescentes pesquisados conferiu um novo significado à internação em relação a sua estrutura física. Ao fotografar o corredor da casa onde ficam abrigados, os adolescentes buscaram demonstrar uma realidade diferente da apontada pelos relatórios e conhecida da sociedade, como descreve Xande, 16 anos: (figura 2) "Tirei a foto da casa pra o povo saber que num tamo num lugar que é pequeninho, que nem o povo pensa que é, um monte de gente tudo junto, não é assim o povo embolado, a casa é grande".

Assim, os adolescentes pesquisados percebiam que a unidade em que se encontravam apresentava, em suas dependências, amplos espaços físicos, tanto dentro das casas, como em seus espaços comuns, que são arborizados e bem cuidados, além de oferecer espaços de lazer que chamam a atenção de quem chega à unidade.

Dinho, 19 anos, relatou que, ao fotografar o corredor de entrada da unidade, quis mostrar que: (figura 3) "Quando a gente chega (...) se deparamos com (...) um clube, muitos fala que é um clube, porque a unidade tem estruturas de um clube, tem jardim, tem piscina, campo de futebol, tem lazer, escola, cultura, hortas, oficinas (...)".

A preocupação em transmitir uma imagem de beleza ao local da internação, diferente da imagem construída acerca desses espaços, também pode demonstrar uma tentativa, por parte desses adolescentes, de

\footnotetext{
${ }^{5}$ Casa, nome dado pela unidade aos alojamentos, por sua semelhança com casas, já que possuem quartos individuais ou para um número limitado de até seis adolescentes, diferindo dos grandes espaços, comuns nas unidades de internação.
}

elaborar um novo significado à privação de liberdade. Se partir do pressuposto de que, ao elaborar significados, os sujeitos atuam sobre estes, modificando-os, os adolescentes desta pesquisa parecem buscar, por meio do relato de suas próprias interpretações, modificar os significados construídos, histórica e socialmente, sobre a instituição e, consequentemente, sobre os adolescentes nela inseridos.

Ao tentar mostrar uma unidade diferente das relatadas pelas inspeções, pela mídia e pelo que faz parte de como as pessoas fora dos muros imaginam, os adolescentes pesquisados demostraram preocupação em mudar o olhar da sociedade, não apenas em relação à instituição em si, mas, principalmente, em relação a cada adolescente que se encontra dentro dela e que sofrerá um processo de estigmatização ao sair de seus muros.

Imaginar uma unidade de internação em que adolescentes são mantidos aglutinados, sob situações humilhantes e de total falta de respeito aos direitos humanos, leva a sociedade a outro olhar tão cruel quanto em relação às próprias unidades, mas que agora se dirige diretamente aos próprios adolescentes privados de liberdade. Um olhar estigmatizante que os coloca como incapazes de mudar sua trajetória de vida, afastando-se da criminalidade.

De acordo com as palavras abaixo, pode-se notar que as pessoas não acreditam na possibilidade de mudança, colaborando para manter o estigma de infrator. O estigma em relação aos adolescentes "infratores" é compartilhado socialmente e, portanto, por profissionais que atuam nas unidades: "Mas se contar tem muitos aí que não tinha chance. $K$ (ex-interno) não tinha chance, tá trabalhando no banco. Que ninguém dava nada e chegou lá fora 


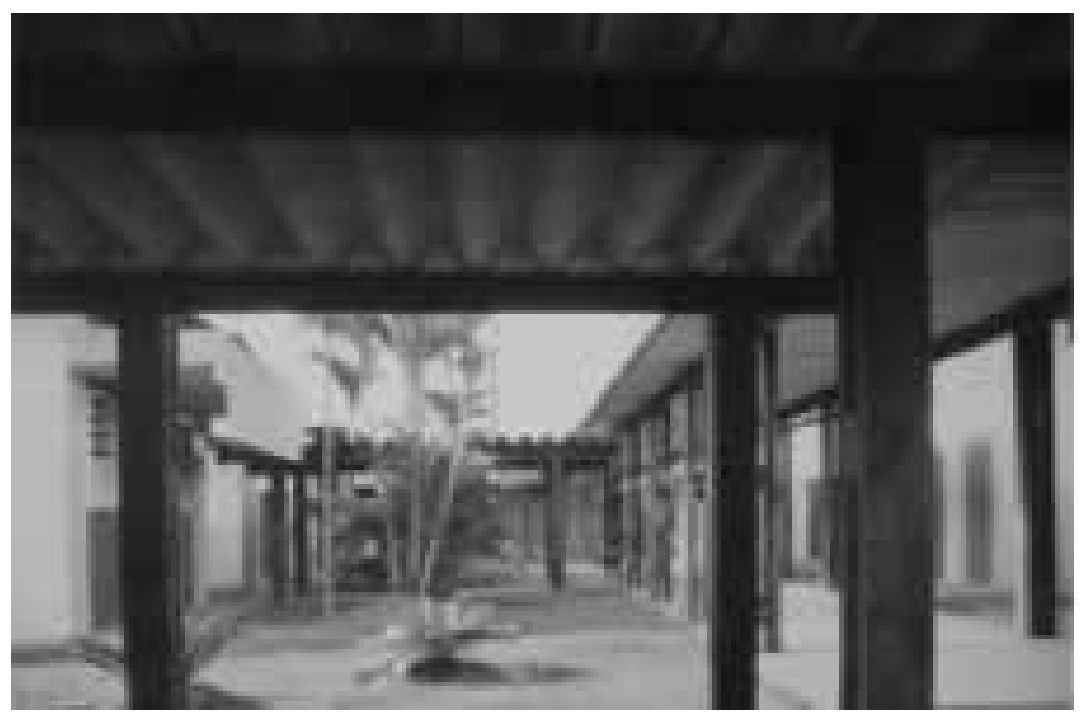

Figura 3. Corredor de entrada.

e mudou. As pessoas (todas) achando que ele não mudava" (Belo, 16 anos).

O estigma era utilizado pelos gregos, conforme coloca Goffman (1891/2004), "para se referirem a sinais corporais com os quais se procurava evidenciar alguma coisa de extraordinário ou mau sobre o status moral de quem os apresentava" (p.5). De acordo com $\mathrm{o}$ autor, o estigma se refere à situação em que os indivíduos não são aceitos plenamente pela sociedade, seja por atributos físicos, como as deficiências; de caráter individual, como a vontade fraca, a desonestidade, atribuídos aos prisioneiros, viciados, desempregados, etc., seja por atributos de classe, relacionados à raça, nação e religião, além das questões socioeconômicas (Goffman, 1891/2004).

A sociedade estabelece formas de categorizar os indivíduos e normalizar o que considera comum ou natural dentro dessas categorias, além de estabelecer os ambientes em que essas categorias têm maior probabilidade de existir (Goffman, 1891/2004). Entre os adolescentes, a crença parte do princípio de que a mudança e a saída da criminalidade são raramente possíveis, colocando-os em uma situação de estigmatização dentro e fora das unidades.

De acordo com a fala de Belo, 16 anos, sobre outro adolescente "desacreditado", se pode perceber o estigma existente em relação aos adolescentes institucionalizados e a desconfiança em relação ao seu comportamento na própria unidade e, com isso, as suposições em relação ao seu futuro: " $L$. $A$. (ex-interno),
- bicho aprontava muito (...) Muitos achavam que ele não ia melhorar, que tinha aceitado Deus só porque estava aqui dentro, quando ele saísse não ia continuar, e ele tá de boa. Os irmãos (religiosos que realizam o culto) falam com ele".

As atitudes frente ao estigmatizado, e os atos empreendidos na relação com este, são respostas que demonstram "discriminações, através das quais efetivamente, e muitas vezes sem pensar, reduzimos suas chances de vida" (Goffman, 1891/2004, p.8). Ao se construir a teoria do estigma, elabora-se uma ideologia para explicar a inferioridade, no caso dos adolescentes, sua periculosidade. A mídia surge novamente como uma das responsáveis por essa ideia de violência e de perigo, atrelada à juventude, ao realizar uma "super-exposição de atos infracionais violentos como se fossem os mais frequentes, aumentando a sensação de insegurança e alimentando uma cultura de medo e de punição" (Cruz, 2010, p.148).

De acordo com Goffman (1891/2004), quando a estigmatização está associada à admissão do indivíduo a uma instituição, como as do sistema prisional, "a maior parte do que ele aprende sobre o seu estigma ser-lhe-á transmitida durante o prolongado contato íntimo com aqueles que irão transformar-se em seus companheiros" (p.34). Portanto, essa relação que se estabelece entre o estigmatizado e instituição a que ele pertence em virtude de seu estigma é crucial para a formação da identidade desse indivíduo.

Assim, ao se falar do adolescente autor de ato infracional, coloca-se esse sujeito em categorias implícitas, 
“adolescente infrator" ou “ex-interno", e é provável que algumas características singulares e historicamente imbricadas nessas categorias, atuem na relação que se tem com essa pessoa, trazendo consigo previsões em relação a sua conduta e sua natureza, pautadas em padrões e marcas sociais. Essa categorização também poderá atuar na construção de uma identidade edificada no sentimento de incapacidade e inferioridade, trazendo o receio quanto ao retorno à comunidade $\mathrm{e}$ quanto ao futuro; receio pautado no estigma impresso pela sociedade a estes sujeitos (Nuñez \& Pernas, 2010).

Faz-se necessário, portanto, que os profissionais que atuam nas instituições possam propiciar a esses adolescentes reformular sua identidade pessoal e social, pautada, até então, no estigma de "criminoso". $\mathrm{O}$ ambiente institucional deve proporcionar a busca de novas identificações que permitam ao adolescente pensar em novas possibilidades e formas de atuar no mundo para que, ao sair, possa recomeçar seu percurso baseado em novas interações sociais e formas de lidar com as possíveis dificuldades, distantes da vivência infracional.

Embora se percebam "presos" e, em dados momentos, revelem aspectos contraditórios aos apresentados anteriormente, como o aprisionamento, indicado por meio das imagens de grades (figura 4) e muros que cercam a instituição, o fato de terem regras rígidas a serem seguidas, que os impedem de fazer o que desejam, a descrença social em sua mudança, o distanciamento do convívio familiar e social, bem como o sofrimento por ter perdido a liberdade, os adolescentes pesquisados apresentam um discurso mais voltado a destacar os pontos positivos da internação. Isso os conduz a pensar a internação como um processo de reflexão e conscientização e que lhes garante o acesso a direitos não vivenciados anteriormente, como escolarização, saúde, profissionalização, além da vivência de atenção e respeito nas relações. Assim, emerge para eles, nessa situação, que esse período pode ser uma chance de rever e repensar seus atos e, principalmente, uma possibilidade de mudança em sua trajetória infracional. Esses resultados apresentam uma forma de pensar a privação de liberdade distante de uma realidade que se pauta apenas na opressão, na violência e na exclusão.

\section{Algumas Considerações}

Os sujeitos desta pesquisa revelaram, nas suas falas, sentidos e significados ambíguos em relação à estrutura física dessa unidade de internação, que, por um lado, mantém aspectos de um "presídio" e, portanto, de privação de liberdade, como as grades, contenções, guaritas e muros. E, por outro lado, tem aspectos relativos à beleza e ao prazer, como a praça arborizada e os amplos espaços de lazer, que mais lembram um clube.

Contudo, a aparente aceitação frente aos aspectos negativos da privação de liberdade, que parecem ter sido minimizados no discurso dos adolescentes pesquisados e a exacerbação de suas características positivas podem estar relacionadas à vivência nesses espaços.

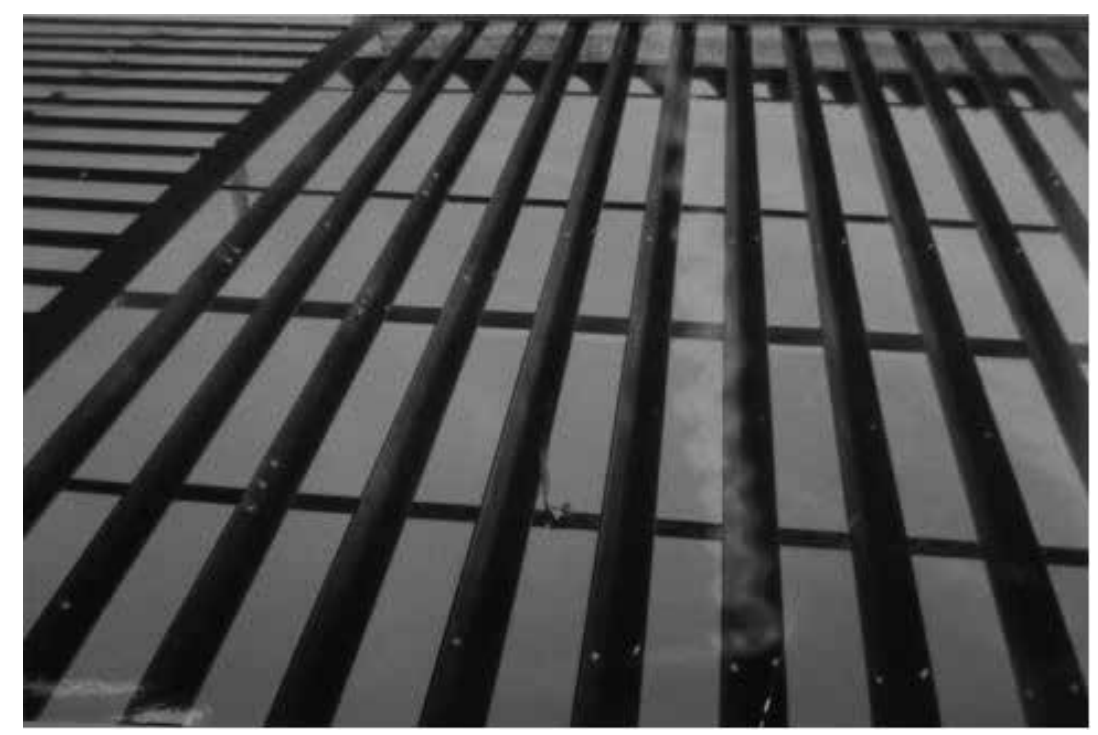

Figura 4. Grade. 
O adolescente talvez tenha se habituado aos aspectos que remetem a instituição a um sistema prisional, de forma que essas imagens passaram a não afetar mais seus sentimentos em relação à internação e a não serem vistas como algo que poderia ser diferente. Ao contrário, os adolescentes passaram a percebê-las como algo que está posto, que faz parte dessa realidade institucional. Considera-se, também, a possível "contaminação" produzida pela forma como os educadores de medida significam a instituição, ressaltando constantemente seus aspectos positivos. De acordo com Goffman (1961/2001), ao viver em uma instituição total, os indivíduos passam por uma "exposição contaminadora" (p.31), pois ocorre uma violação das ligações do sujeito com seu mundo exterior e o sujeito é contaminado pelo ambiente que o cerca.

Vale aqui ressaltar o movimento dialético que envolve a abordagem utilizada nessa pesquisa, que parte do pressuposto de que o indivíduo age sobre o contexto que o cerca e é influenciado por ele (Vigotski, 1986/1995, 1978/2003), mesmo que as ações envolvam contradições ou opostos. Ao conviver com as várias feições da privação de liberdade, negativas e positivas, o adolescente pode passar a percebê-las como naturais, ou obrigatórias daquele espaço, e/ou necessárias para sua "recuperação" e "reinserção" social, passando a incorporá-las em sua rotina diária, sem qualquer crítica ou reflexão.

Mas, há que se considerar também que se trata de uma unidade que difere da maioria das instituições socioeducativas em estrutura física e profissional, em atendimento aos pressupostos legais de garantia de direitos e na forma de tratamento, de forma a proporcionar, aos internos, um distanciamento da violência a que estão expostos em seu convívio diário. Em vista disso, ressaltar seus pontos positivos de maneira tal que eles se sobrepõem aos aspectos negativos inerentes à privação de liberdade, como a opressão, a estigmatização, a despersonalização e a exclusão, características do discurso de sujeitos aprisionados, pode denotar uma nova construção de sentidos, por partes desses adolescentes, pautada na vivência nessa instituição específica.

Os muros e as grades que limitam a liberdade e que os distanciam do convívio social são também os muros e as grades que delimitam um espaço em que é possível pensar além da punição, característica do sistema prisional, além do ato infracional, que o estigmatiza, além da privação de direitos a que são expostos, mas pensar em um lugar de acolhimento, de atendimento, um lugar que possibilite a construção de novas identidades, diferentes das impostas pela sociedade a esses sujeitos.

Essa contradição, verificada nos discursos desses sujeitos, aponta um distanciamento entre os sentidos elaborados por esses adolescentes sobre a internação e os significados sociais acerca dessa medida, demonstrando certo protagonismo construído a partir da vivência da privação de liberdade nessa instituição, uma experiência que possibilita a construção de novos sentidos, em uma direção que se afasta das significações sociais. Esse processo demonstra, novamente, o movimento dialético indivíduo-ambiente, apontado por Vigotski (1986/1995, 1978/2003), que perpassa a construção de sentidos e significados e que pode proporcionar mudanças, tanto no sujeito quanto no ambiente que o cerca.

Os resultados, portanto, indicam que é possível criar espaços de atendimento mais humanizados e nos quais os direitos humanos sejam respeitados; apontam, ainda, o apelo dos adolescentes para uma mudança nas significações construídas por funcionários do sistema socioeducativo e pela sociedade como um todo, a respeito das instituições de cumprimento de medida socioeducativa de internação e, consequentemente, em relação aos adolescentes.

O significado histórico construído acerca do adolescente autor de ato infracional, e das motivações que o levam ao ato, determina as ações voltadas a esses sujeitos, que são pessoais, políticas, sociais e profissionais. Torna-se necessária, portanto, uma revisão na forma de olhar e, principalmente, atuar junto a essa população, na medida em que o adolescente se apropria dos significados sobre si, e esses significados passam a mediar suas relações e sua constituição, o que pautará suas ações em relação ao mundo, num movimento de (re)produção ou (trans)formação da realidade e da sua relação com esta realidade (Padovani, 2013).

O grande desafio das unidades de internação é buscar uma maneira de contribuir para modificar a situação de vulnerabilidade a que são expostos esses adolescentes, por meio de atividades de cunho socioeducativo, que possibilitem a esses adolescentes percebê-las como uma fonte de transformação da sua realidade (Silva, Ruzzi-Pereira, \& Pereira, 2013).

Contudo, falar de uma unidade "modelo" remete a pensar em suas implicações, principalmente, no se refere à construção das expectativas desses adolescentes em relação ao futuro fora da instituição. Construir unidades-modelo pode ser visto como um caminho para atender aos adolescentes autores de ato infracional 
de forma mais humanizada, porém não deve ser o único. A implantação de medidas socioeducativas em meio aberto e com a participação ativa da família, da comunidade e da sociedade civil como um todo, deve estar em pauta como uma opção urgente à internação.

Sabe-se que é, no mínimo, incoerente, excluir com vistas a incluir, e que educação e repressão não podem caminhar juntas. Portanto, a discussão deve considerar que, se por um lado não se pode simplesmente "extinguir" essas unidades, por outro é necessário pensar que segregar já em é, em si, desumanizar. Assim, alternativas devem ser buscadas fora dos muros, com vistas a trazer transformações para esses sujeitos que, por inúmeras razões, envolveram-se em atos infracionais. A internação leva a mais um estigma, além de "infrator", agora "ex-interno".

O debate, assim, deveria ser contrário ao que tem sido realizado pela sociedade, contrário ao que expõe a mídia: ao invés de se erguerem unidades cada vez mais fechadas, ou mesmo, mais "humanizadas", o grande desafio que se faz presente e urgente é justamente esvaziá-las, construindo uma sociedade menos punitiva e violenta, e mais educativa (Cruz, 2010). Mas, isso só é possível alcançar com medidas que não restrinjam direitos, entre eles o direito à liberdade.

A discussão sobre a maioridade penal é um bom exemplo de como a sociedade tem buscado lidar com seus conflitos e questões relacionadas à juventude, em que a repressão se torna o caminho para a adequação das condutas, conforme aponta Cruz (2010). Reduzir a idade penal não é condição para reduzir a violência. Reduzir a desigualdade social pode ser um caminho. A ameaça não previne violência e a punição não a corrige.

A experiência na área socioeducativa tem demonstrado que, quando inseridos em programas que possibilitem a inserção profissional e a escolarização, os adolescentes constroem trajetórias distantes da vida infracional e que o oposto também é verdadeiro. Sem perspectivas e sem acompanhamentos eficazes, o retorno à criminalidade é o caminho possível para muitos adolescentes egressos do sistema socioeducativo, que carregam consigo o estigma imposto pela passagem em instituições socioeducativas. A mudança que se faz necessária e imprescindível, e que precisa ser debatida, vai muito além da humanização das unidades de internação, ou de mudanças necessárias para sua adequação às leis. Pretender tornar eficaz a ação educativa por trás de muros e grades é, no mínimo, incompatível, visto que as condições reais de sobrevivência e o acesso às oportunidades que esses adolescentes encontram na sociedade não são os mesmos dos que foram oportunizados na instituição.

A sociedade precisa, de forma urgente, perceber que é parte importante da solução quando o tema envolve adolescentes autores de ato infracional. Faz-se necessário o envolvimento de toda sociedade, pois se deve pensar a conduta violenta, tanto de adolescentes como de adultos, inserida em um contexto mais amplo, contexto social e cultural que está longe de ser pacífico, realidade esta que não permite justificar que medidas punitivo-repressivas se sobreponham a medidas socioeducativas.

\section{Referências}

Bock, A. M. B., Gonçalves, G. M., \& Furtado, O. (2011). Psicologia sócio-histórica: Uma perspectiva crítica em psicologia. (5a. ed.). São Paulo: Cortez.

Brasil (2000). Estatuto da Criança e do Adolescente de 1990. São Paulo: Editora Atlas.

Comissão Nacional de Direitos Humanos do Conselho Federal de Psicologia [CNDH-CFP] \& Conselho Federal da Ordem dos Advogados do Brasil [CF-OAB]. (2006). Um Retrato das Unidades de Internação de Adolescentes em conflito com a lei. (2. ed.). Recuperado de www.crpsp.org.br/relatorio_oab.pdf

Costa, A. C. G. da. (1997) Pedagogia da presença: Da solidão ao encontro. Belo Horizonte: Modus Faciendi.

Creswell, J.W. (2014). Investigação qualitativa e projeto de pesquisa: Escolhendo entre cinco abordagens. $3^{a}$ ed. Porto Alegre: Penso.

Cruz, A. V. H. (2010). O adolescente em conflito com a lei e a escola: Criminalização e inclusão perversa (Dissertação de mestrado). Centro de Ciências Humanas, Letras e Artes, Universidade Federal do Rio Grande do Norte, Natal.

Foucault, M. (2002). A Verdade e as Formas Jurídicas. (3 ed.). Rio de Janeiro: NAU Editora (Original publicado em 1996).

Foucault, M. (1987). Vigiar e punir - história da violência nas prisões. (27a . ed.). Petrópolis: Vozes (Original publicado em 1975).

Goffman, E. (2004). Estigma: Notas sobre a manipulação da identidade deteriorada. Tradução: Mathias Lambert (Original publicado em 1891). 
Goffman, E. (2001). Manicômios, prisões e conventos. São Paulo: Perspectiva (Original publicado em 1961).

Gonçalves, H. S. (2011). Sobre a participação da família no processo socioeducativo. In J. Dayrell, M. I. C. Moreira \& M. Stengel, (Eds.). IV JUBRA Juventudes Contemporâneas: Um mosaico de possibilidades. (pp.380-397). Editora PUC Minas: Belo Horizonte.

González-Rey, F. L. (2002). Pesquisa qualitativa em psicologia: Caminhos e desafios. São Paulo: Pioneira Thomson Learning.

Lei no. 12.594 (2012, 18 de janeiro). Institui o Sistema Nacional de Atendimento Socioeducativo (SINASE). Brasília, DF: Recuperado de http://www. planalto.gov.br/ccivil_03/_Ato2011-2014/2012/ Lei/L12594.htm

Melleiro, M. M. \& Gualda, D. M. R. (2005). Explorando a "fotovoz" em um estudo etnográfico: Uma estratégia de coleta de dados. Rev Bras Enferm, 58(2), 191-193.

Mesquita, G. R. (2005). Significados de infância para professores do ensino fundamental (Dissertação de mestrado em Psicologia). Faculdade de Filosofia e Ciências Humanas, Universidade Federal da Bahia, Salvador.

Metring, R. A. Pesquisas científicas: Planejamento para iniciantes. Curitiba: Juruá, 2011.

Neiva-Silva, L. \& Koller, S. H. (2002). O uso da fotografia na pesquisa em Psicologia. Estudos de Psicologia, 7(2), 237-250.

Nuñez, R. A., \& Pernas, L. (2010). ¿Incluir y prevenir o vigilar y castigar? Integración social de jóvenes en conflicto con la ley penal desde una perspectiva comunitaria. Segurança Urbana E Juventude, 3(1), $1-23$.
Padovani, A. S. (2013). Vozes aprisionadas: Sentidos e significados da internação para adolescentes autores de atos infracional (Dissertação de mestrado). Instituto de Psicologia, Universidade Federal da Bahia, Salvador, $200 \mathrm{p}$.

Ristum, M. (2001). O conceito de violência de professoras do ensino fundamental (Tese de doutorado). Faculdade de Educação, Universidade Federal da Bahia, Salvador, $\mathrm{BA}$.

Santos, G. L. dos. (2010). Significados e sentidos dos direitos entre adolescentes de Salvador (Tese de doutorado). Instituto de Psicologia, Universidade Federal da Bahia, Salvador.

Silva J. O. (2009). Produção de sentidos em adolescentes privados de liberdade (Dissertação de mestrado). Instituto de Psicologia, Universidade Federal da Bahia, Salvador.

Silva, D. C. de O., Ruzzi-Pereira, A., \& Pereira, P. E. (2013). Fatores protetivos à reincidência ao ato infracional - concepções de adolescentes em privação de liberdade. Caderno Terapia Ocupacional UFSCar, 21(3), 553-561.

Vigotski, L. S. (2003). A formação social da mente: O desenvolvimento dos processos psicológicos superiores. SP: Martins Fontes (Original publicado em 1978).

Vigotski, L. S. (1995). Pensamiento y lenguaje. Ediciones Fausto. (Original publicado em 1986). Recuperado de http://psickolibro.blogspto.com

Vigotski, L. S. (2006). Obras escogidas tomo IV. Madri: Machado Libros (Original publicado em 1931).

Volpi, M. (2002). O adolescente e o ato infracional. (4ª ed.), São Paulo: Cortez.

Recebido 23/03/2015

Reformulado 01/09/2015

Aceito 21/09/2015 
Sobre as autoras:

Andréa Sandoval Padovani é doutoranda e mestra em Psicologia pela Universidade Federal da Bahia, graduada em Psicologia pela Faculdade Ruy Barbosa (2006), com extensão e capacitação em Prevenção ao abuso de álcool e outras SPA's e em Sistema Nacional de Medidas Socioeducativas e docente do curso de graduação em Psicologia Faculdade Mauricio de Nassau. Exerceu as funções de Coordenadora Técnica e Psicóloga em uma Comunidade de Atendimento Socioeducativo, junto a adolescentes em cumprimento de privação de liberdade. Interesse por pesquisas sobre adolescência em situação de risco e em conflito com a lei, violência e educação, psicologia escolar e educacional.

E-mail: ajpadovani@uol.com.br

Marilena Ristum possui graduação em Psicologia pela Universidade de São Paulo (Ribeirão Preto), mestrado em Psicologia pela Universidade de São Paulo e doutorado em Educação pela Universidade Federal da Bahia. Atualmente é docente associada da Universidade Federal da Bahia, nos cursos de graduação e pós-graduação em Psicologia, orienta alunos de mestrado e doutorado e tem experiência na área de Psicologia, com ênfase Cultura e Sociedade, atuando principalmente nos seguintes temas: violência e escola, bullying escolar, violência e família, violências contra a criança e o adolescente, medidas socioeducativas, psicologia escolar e educacional, relação professor-aluno em escolas públicas e particulares.

E-mail: ristum.ufba@gmail.com

\section{Contato com as autoras:}

Rua Jorge Carneiro Azevedo, 17 Casa 4

CEP: 42700-000

Buraquinho - Lauro de Freitas-BA, Brasil

E-mail: ajpadovani@uol.com.br

Fones: (71) 3369-5148 ou (71) 9166-9334 